\title{
Educação Ambiental e movimentos sociais: espaços paralelos ou compartilhados?
}

\author{
Maria Inês Gasparetto Higuchi ${ }^{1}$ \\ Wilson Moreira Junior ${ }^{2}$
}

Resumo: Tem sido cada vez mais constante ficarmos perplexos com a baixa expressividade da consciência das pessoas e as morosas mudanças no comportamento ecológico. Tanto a Educação Ambiental quanto os movimentos sociais, como campos de ação social, se propõem a transformar esse cenário. Entretanto, vemos que, apesar desses propósitos compartilhados, não raro atuam em espaços paralelos. Essa situação requer uma reflexão tanto das perguntas como das respostas a essa problemática. Destacamos dois pontos debatidos em grupo no V EPEA, em 2009, os quais, longe de serem exclusivos, nos auxiliam nessa reflexão tendo a Educação Ambiental e movimentos sociais como espaços de luta socioambiental. O primeiro se refere aos aspectos de atuação da EA e dos MS na busca de respostas fortes, e o segundo é relativo ao papel da academia na aglutinação desses espaços para transcender a pura investigação de perguntas fortes e incluir respostas fortes.

Palavras-chave: Educação Ambiental, Movimentos Sociais, Sociedades Sustentáveis.

Abstract: Nowadays we are getting more and more amazed by people's low expressivity of consciousness and by how slowly social behavior towards the environment changes. Environmental Education (EE) and social movements (SM) are important paths through which we can transform such reality. However, even considering similar goals within these social action domains, in many cases they work as separate domains. In order to understand this scenario, it is relevant to think not only of what is happening but of what is the nature of such situation. From this perspective, it is necessary to reflect on the kind of questions we are asking and on what kind of answers we are providing when dealing with ecological problems. This paper examines two points, among many others, that were discussed in a group at the $\mathrm{V}$ Research Meeting on Environmental Education (EPEA), occurred in 2009. The first point refers to the importance of $\mathrm{EE}$ and SM spaces in providing strong questions about people-environment relations. The second point is the discussion about the academic contribution to the creation of effective democratic spaces that goes beyond simple investigation to include strong answers.

Keywords: Environmental Education, Social Movements, Sustainable Societies.

1 Doutora em Antropologia Social e pesquisadora titular do Lab. de Psicologia e Educação Ambiental do Instituto Nacional de Pesquisas da Amazônia (INPA). Av. André Araújo, 2936, Aleixo, Manaus-AM CEP 60.060-001 E-mail: mines@inpa.gov.br

2 Mestre em Pesca e graduando em Ciências Sociais - UNESP. E-mail: wilmorjr@hotmail.com 
Tanto a Educação Ambiental (EA) quanto os movimentos sociais (MS), enquanto campos de ação social, têm, em sua estrutura de organização, metas de atuação integradoras que se distinguem de padrões vigentes, notadamente divisores. Portanto, está no âmago dessas proposições um caráter transformador das relações das pessoas com o mundo humano e geofísico. Ademais, ambos se mostram como processos estratégicos na formação de uma consciência crítica e de emancipação dos indivíduos.

Muito se tem falado que a EA não é somente um ato de transmissão de conhecimento sobre o ambiente, mas um processo pelo qual se busca ampliar a participação política das pessoas na consolidação da democracia plena. É certo que a EA, como nos alerta Santos (2003), pode ser em si uma democratização de práticas sociais, porém, ela nunca chegará a se democratizar o suficiente se o conhecimento que a orienta não for ele próprio democratizado. $\mathrm{O}$ autor não compartilha da ideia de que o conhecimento científico é o único produtor de racionalidade política e social e se refere, sobretudo, aos saberes daqueles que são reprimidos e excluídos. Dessa forma, as práticas sociais devem estar coladas na democracia dos saberes. A EA e os MS devem, pois, mediar a apropriação do conhecimento pela sociedade e a transformação necessária.

Isso requer uma educação política de modo a preparar as pessoas para intervenções sociais, na intenção de mudar as relações dos seres humanos entre si e destes com o meio ambiente para a construção de uma sociedade sustentável (REIGOTA, 1994). Por sociedade sustentável deve-se entender não só um meio ambiente equilibrado mas o combate à pobreza, a garantia de moradia digna, saúde, segurança alimentar, democracia, respeito aos direitos humanos, paz, respeito à diversidade cultural e às comunidades tradicionais (PELICIONI, 2000).

É evidente a expansão que a EA tem atingido em muitos segmentos sociais e nas políticas públicas (VASCONCELOS et al., 2009). Muitas estratégias, tais como as redes sociais e fóruns de discussão, foram, sem dúvida, um avanço significativo nessa expansão. Essas vozes foram ouvidas, mesmo que em dado momento tenham ou emudecido, ou diminuído o volume, deixando lacunas que merecem ser desnudadas, revistas e refletidas (REIGOTA, 2008).

Por ser um ato político com base em valores para a transformação social, a EA não é neutra, mas ideologicamente comprometida com paradigmas pautados na conquista da cidadania para uma sociedade justa e um ambiente equilibrado (LOUREIRO, 2002). O compromisso político inerente à EA considera que a liberdade e a justiça são as bases inegociáveis da sustentabilidade, e não pode ser confundido com filiação partidária (REIGOTA, 2005). Ao integrar-se às forças emancipatórias sensíveis às lutas socioambientais, a EA 
incorpora os processos decisórios participativos como um valor fundamental na proteção ambiental. Tem-se desse modo o desafio de criar as condições para a participação nas políticas públicas, bem como para a sua ampliação, em qualquer momento e em qualquer que seja a gestão partidária.

Segundo Layrargues (2002), ainda falta no Brasil um longo caminho a ser percorrido para que se firme uma cultura democrática enraizada em toda a sociedade brasileira. Enquanto não se afirmar uma democracia efetiva e toda a sociedade não puder discutir seus interesses e caminhar em direção à sustentabilidade ambiental e justiça social, diferentes segmentos continuarão a ser expropriados de seus direitos a uma vida digna, aos seus territórios e à sua identidade cultural, principalmente as parcelas da população com menor poder aquisitivo e as de comunidades tradicionais.

Ao assumir-se que a EA é um instrumento de educação política e que prepara as pessoas para exigir justiça social, cidadania, autogestão e ética nas relações sociais e com a natureza (REIGOTA, 1994), ela precisa trabalhar com referenciais que propiciem a autonomia popular e organização social, sem que o Estado, seja de direita ou esquerda, interfira nesse direito. A organização civil favorece a força motriz para as transformações nas políticas públicas de emancipação das pessoas.

Entretanto, tais referenciais não parecem tão fáceis como se tem alardeado. Santos (2008) nos alerta de que precisamos nos dar conta de que, por estarmos vivendo um tempo de transição paradigmática, nos deparamos com uma problemática em que há "perguntas fortes e respostas fracas", protagonizadas não necessariamente por aqueles que expropriam à luz do dia, mas por instituições e organizações autodesignadas como promotoras de um novo mundo, onde as teorias e práticas se distanciam a olho nu, já que, conforme o autor, muitos movimentos sociais contradizem os princípios convencionais que propalam, mostrando claramente o seu pouco esclarecimento e ações retrógradas. Constantemente, somos informados da proliferação de movimentos sociais cujas bandeiras de defesa se parecem; entretanto, pouco realmente se conhece dessas trajetórias e poucos poderiam ser considerados como movimentos sociais, tendo em conta suas práticas. Não é raro nos depararmos com discursos em que há a luta por um aparelhamento de ideias que mascara ideologias hegemônicas, mesmo de esquerda.

Em muitos momentos, verificamos, perplexos e demasiado tolerantes, quase imobilizados, a baixa expressividade da qualidade da consciência de todos, as morosas mudanças no comportamento ecológico e os equívocos cometidos em nome de interesses que ignoram deveres óbvios de uma ética coletiva. É indubitável que qualquer tentativa de hegemonia, em qualquer temática, sob 
qualquer ideologia, produz alienação e dominação, mesmo que isso seja pensado como uma única forma de atingirmos uma meta supostamente transformadora. Santos (2008) alerta que há uma diversidade de compreensão do que se entende como dignidade humana e justiça social, e por isso defende a base sacramental das escolhas diante das possibilidades. Porém, o autor reconhece que há os que apenas se prostram diante dessa realidade e os que fazem dela a força motriz para atingir e criar novas possibilidades, mesmo que isso implique riscos.

Diante desses fatos, não podemos apenas contemplá-los com perplexidade. Ao contrário, isso nos mostra a necessidade de uma sistemática avaliação de pontos que não são inéditos, estão sempre emergentes em nosso cotidiano. Essa situação requer um debate tanto da gênese do problema em si quanto da formulação de ações eficazes e efetivas que permitam a construção de um novo repertório de comportamentos verdadeiramente emancipatórios. Destacamos dois pontos que, embora não sejam exclusivos, se mostram importantes na trajetória de construção da almejada cidadania tendo a Educação Ambiental como aliada dos movimentos sociais. Esses pontos foram refletidos no Grupo de Discussão de Pesquisas Educação Ambiental e Movimentos Sociais por ocasião do V EPEA, ocorrido em São Carlos, SP, em 2009. O primeiro se refere aos aspectos de atuação da EA e dos MS, se estes se constituem como espaços distintos ou complementares na busca de respostas fortes. O segundo é relativo ao papel da academia na aglutinação desses espaços para transcender a pura investigação de perguntas fortes e incluir respostas fortes.

Ao problematizarmos pontos constitutivos da EA e dos MS, podemos encontrar vários trabalhos que têm se ocupado da discussão das gêneses e processos históricos que permeiam esses dois campos de ação, culminando na produção de interessantes aspectos críticos (CARVALHO, 2001; LOUREIRO, 2002, 2008; VASCONCELOS et al., 2009). Em primeiro lugar, esses dois segmentos compartilham em sua essência a mesma práxis epistemológica? Poderíamos dizer que alguém, por estar envolvido em MS, seria capaz de ter a temática ambiental incorporada ao seu fazer e pensar? Ou, de outra forma, alguém envolvido em ações ecológicas/ambientalistas teria como base a emancipação e crítica incondicional em todos os momentos de sua trajetória política? Será que não estamos continuando a tratar a EA como aspecto distinto do que entendemos como "movimento social"?

Nossa reflexão adentra a dificuldade intrínseca de considerarmos a indissociabilidade constitutiva, o que historicamente tem nos incapacitado de compreender e viver o social e ecológico/ambiental como aspectos de uma mesma realidade. Considerando que os problemas ambientais são, sem dúvida, aspectos das relações sociais (HIGUCHI, 2002; HIGUCHI; AZEVEDO; 
FORSBERG, 2004), como a EA se insere nos MS, e vice-versa? Essa trajetória é realmente compartilhada ou apenas paralela? Não estaríamos diante de uma reprodução indesejável de fragmentação da realidade, na qual apenas conseguimos andar um ao lado do outro? Onde e como a EA floresce e se consolida como parte de um novo movimento social?

Podemos observar que a simples existência do debate dessas distinções nos mostra nossa dificuldade, ou resistência, em unificar aquilo que equivocadamente insistimos em fazer separado. Diante desse complexo cenário socioambiental, temos questões bastante profundas, como, por exemplo, a de como nos constituímos como pessoas e formamos nosso conhecimento, valores, ideologias, afetividades, entre outros, que estão subjacentes às nossas práticas pessoais e coletivas.

O ser humano, como ser biologicamente social, constrói seu conhecimento, seu sistema de significados da realidade na interação com outras pessoas e as reelabora num processo dinâmico e contínuo, de forma que as concepções são ao mesmo tempo repetidas e modificadas. E é justamente transformando tais concepções que a pessoa acaba por transformar-se. Desse modo, o processo de construção do conhecimento, baseado na subjetividade e intersubjetividade, ocorre num intrigante engajamento das mais variadas e complexas redes de significados da vida social e suas instituições (TOREN, 1993).

Certas práticas se difundem nos grupos sociais e acabam por conformar comportamentos e costumes que se reproduzem e se reconstroem entre os membros daquela coletividade. Esse saber comum é construído não apenas por vivências mas principalmente pela convivência, o que garante a característica de produto e produtor na construção do conhecimento (BERGER; LUCKMANN, 1991; BOURDIEU, 1977; DALLARI, 2003; HELLER, 1977; MOSCOVICI, 1989; NORTON, 2009; TOURAINE, 1994).

Esses domínios micro e macro-históricos são inseparáveis na constituição do agente social enquanto ser único, singular e membro de um determinado grupo. Por isso, devem ser contemplados como fatores importantes e decisivos em qualquer atividade educativa ou mobilização social. Desconsiderando-se esses princípios básicos, corre-se o risco de introduzir ou maximizar conflitos de dimensões significativas diversas. Não que o conflito seja, por si só, algo intolerável, mas o processo educativo deve permitir reconhecê-lo e enfrentá-lo.

Para andarmos em nossa proposta de reflexão, é indubitável conhecer de modo sistemático o que realmente acontece na interface EA-MS. Vários movimentos sociais são constituídos tendo a questão ambiental como eixo 
unificador e identitário coletivo (ALMEIDA, 2006, 2008). Diante disso, poderíamos considerar que ao incorporar aspectos ecológicos/ambientais um movimento social se configuraria como "completo"? A ausência da dimensão ambiental prenuncia a corrosiva fragmentação da realidade? Estaria ela mostrando a dificuldade de enxergarmos um agente social munido de toda a teia que o constitui? Como aspectos pessoais e coletivos se distinguem nos processos de mobilização e participação socioambiental? Persiste e certamente incomoda muitos a falta de melhores evidências sobre as necessidades de convivência e mobilização em torno de lutas coletivas, que superem a individualização e egocentrismo bastante evidentes. Como avançar nesses pontos? $\mathrm{Na}$ falta de respostas precisas, valeria a pena pensarmos esses aspectos aqui pontuados, que, embora não sejam únicos nem mais importantes, nos posicionam na atitude rumo a respostas fortes que Santos (2008) nos apresenta. Nas reflexões produzidas em grupo, foram levantados questionamentos relativos às orientações metodológicas acerca das pesquisas em EA nesse âmbito e, em particular, a como esta se dá ou se aproxima dos ideais que deram origem aos MS e suas lutas. Tendo em conta o papel e função social da academia, quer seja o de investigação, questionamento ou produção acadêmica, é inevitável nos perguntarmos se estaríamos avançando no entendimento de algumas questões que nos imobilizam diante do fraco desempenho de transformações do comportamento ecológico e social.

Será que com nossas investigações estamos contribuindo o suficiente para promover mudanças na práxis da EA? Tais métodos estão "revolucionando" politicamente a construção da cidadania? Os estudos de investigação em uso estão realmente sendo conduzidos pela proposta protagonista de compreensão desses aspectos de forma mais abrangente? Quais são as fragilidades dos estudos na apreensão dessa complexidade e na proposição de ações mais efetivas em busca de uma produção de sentido que transcenda aspectos unicamente ideológicos? Os resultados de investigações acadêmicas, descritas sob tal paradigma, têm surtido os efeitos desejados num tempo necessário? Estariam ainda predominando teorias convencionais em que o saber popular é visto como secundário diante do saber científico?

É a partir desses e de outros questionamentos que a academia teria o papel imparcial de apresentar as realidades postas em campo, fazendo uso de ferramentas que permitam uma resposta forte. Apesar do reconhecido papel na mediação do processo de emancipação dos cidadãos, a academia ainda enfrenta dilemas de como se aproximar dessa práxis. Reconhecemos que, diante de fenômenos inéditos, são necessárias novas teorias sociais e novos conceitos analíticos (SANTOS, 2008). É consenso entre pesquisadores que atuam em EA e 
MS a necessidade de pesquisas e métodos orientados para essa realidade com o mesmo rigor estabelecido nas demais esferas de acontecimentos. As questões que embasam tais investiduras são variadas e polissêmicas, porém, não raro, estamos evidenciando problemas que se repetem continuamente. Cabe-nos refletir se os métodos utilizados pelos pesquisadores para estudar a inserção da EA no contexto dos MS nos permitem avançar além da identificação do problema.

A identificação de "respostas fortes" é tão necessária e vital quanto as "perguntas fortes" que procuramos construir (SANTOS, 2008). Nesse viés, vemos que no mundo acadêmico alguns estudiosos já se ocupam em questionar a forma histórica das abordagens majoritariamente individualistas e reducionistas (MORIN, 1996), tanto quanto a objetividade científica e seu corolário imediato de desvendar o objeto de estudo com a suposta e inexistente neutralidade (GUATTARI; ROLNIK, 2000).

Novos campos de trabalho foram produzindo deslocamentos metodológicos que acabaram por se constituir como relevantes e legítimos (PORTUGAL, 2008). A pesquisa não se localiza necessariamente em campos distintos de uma proposta pedagógica, uma vez que esta deva ser inovadora (REIGOTA, 1999), bem como participativa e engajada (JACOBI; TRISTÃO; CORREA, 2009).

A aplicação de métodos de pesquisa pautados em elementos que problematizam permanentemente uma realidade posta, de modo a torná-la sempre aberta e dinâmica, nunca pronta ou universalista - pelo motivo óbvio dessa emergente condição transitável da vida -, deu nova visibilidade e legitimidade às alteridades e às minorias. Metodologias com o rigor científico, mas sensíveis aos movimentos inerentes a essa realidade, vêm se firmando como estratégias acadêmicas de produção investigativa. Tal produção acadêmica vem gradativamente questionando o isolamento e dominação do "pesquisado" e incorporando em seu fazer metodológico posicionamentos políticos e éticos. Mais que isso, vem atuando responsavelmente na realidade investigada.

Nesse sentido, a pesquisa-ação participativa (LÓPEZ-CABANAS; CHACÓN, 2003), ou pesquisa-intervenção (CASTRO; BESSET, 2008), se caracteriza não apenas como um método mas como um paradigma com múltiplos métodos possíveis que possibilita um modo de pesquisar e compreender o objeto de estudo de tal forma que a este seja incorporada uma aproximação do pesquisador e pesquisado, principalmente junto aos grupos politicamente minoritários. Problematizam-se, assim, as diferenças e retoma-se o princípio já apresentado nos estudos de Kurt Lewin, de que atuar sobre a 
realidade seria uma estratégia para ir além de conhecê-la e poder transformá-la (LOUREIRO, 2002).

Isso implica um ethos do pesquisador cuja base é o comprometimento com a ação de transformação social por meio do diálogo, da mediação e da crítica (FREIRE, 1983), e não o mero desvendar de um cenário, dando aos demais agentes sociais a responsabilidade exclusiva de busca de soluções. Essa estratégia acadêmica, no entanto, não é apenas uma renovação de forças, mas um campo de incertezas, e, como diz Portugal (2008), de "desamparo" do pesquisador. Desamparo por exigir o protagonismo de criar novos modos de investigação distantes de métodos já consagrados. As incertezas, por sua vez, próprias de um fazer em construção que se propõe a inovar metodologias, compõem um campo de complementação que exige um esforço bastante grande para responder aos questionamentos que se apresentam na esfera científica.

Diante de tantos questionamentos, consideramos na reflexão grupal que muito ainda temos que avançar como protagonistas de uma transformação da sociedade com comportamentos sustentáveis. Temos que avançar como cidadãos e, em especial, problematizar o diálogo da Educação Ambiental com os demais campos de ação e reflexão, seja a academia ou movimentos sociais, uma vez que todos constituem espaços compartilhados e indissociáveis na luta por uma sociedade verdadeiramente sustentável.

\section{Referências}

ALMEIDA, Alfredo Wagner Berno de. Terras de quilombo, terras indigenas, babacuais livres, castanbais do povo, faxinais e fundos de pasto: terras tradicionalmente ocupadas. Manaus: PPGSCA-UFAM, 2006.

- Antropologia dos Arcbivos da Amazônia. Manaus: Casa 8; Fundação Universidade do Amazonas, 2008.

BERGER, Peter; LUCKMANN, Thomas. A construção social da realidade. 9. ed. Petrópolis: Vozes, 1991.

BOURDIEU, Pierre. Outline of a Theory of Practice. Cambridge: Cambridge University Press, 1977.

CARVALHO, Isabel Cristina de Moura. Educação Ambiental e Movimentos Sociais: elementos para uma história política do campo ambiental. Educaşão: Teoria e Prática, Rio Claro, v. 9, n. 16-17, p. 46-56, 2001.

CASTRO, Lucia Rabelo de; BESSET, Vera Lopes. Pesquisa-intervenção na infância e jwventude. Rio de Janeiro: FAPERJ; NAU, 2008.

DALLARI, Dalmo de Abreu. Elementos da teoria geral do Estado. São Paulo: Saraiva, 2003. 
FREIRE, Paulo. Pedagogia do Oprimido. 13. ed. Rio de Janeiro: Paz e Terra, 1983.

GUATTARI, Félix; ROLNIK, Suely. Micropolítica: Cartografias do Desejo. 4. ed. Petrópolis: Vozes, 2000.

HELLER, Agnes. O cotidiano e a história. 3. ed. Rio de Janeiro: Paz e Terra, 1977.

HIGUCHI, Maria Inês Gasparetto. Psicologia Ambiental: uma introdução às definições, histórico e campos de estudo e pesquisa. Canoas: ULBRA, 2002. (Cadernos Universitários, n. 49).

HIGUCHI, Maria Inês Gasparetto; AZEVEDO, Genoveva Chagas de; FORSBERG, Sylvia Sousa. A Floresta e a sociedade: história, idéias e práticas. In: HIGUCHI, Maria.Inês Gasparetto; HIGUCHI, Niro (Ed.). A floresta Amazônica e suas múltiplas dimensões: uma proposta de educação ambiental. Manaus: INPA; CNPq, 2004.

JACOBI, Pedro Roberto; TRISTÃO, Marta; FRANCO, Maria Isabel Correa. A função social da educação ambiental nas práticas colaborativas: participação e engajamento. Cad. CEDES, Campinas, v. 29, n. 77, p. 63-79, abr. 2009.

LAYRARGUES, Philippe Pomier. Educação para a gestão ambiental: a cidadania no enfrentamento político dos conflitos socioambientais. In: LOUREIRO, Carlos Frederico B.; LAYRARGUES, Philippe Pomier; CASTRO, Ronaldo Souza de (Org.). Sociedade e meio ambiente: a educação ambiental em debate. São Paulo: Cortez, 2002.

LÓPEZ-CABANAS, Miguel; CHACÓN, Fernando. Intervención psicosocial y servicios sociales. Un enfoque participativo. Madri: Sintesis Psicología, 2003.

LOUREIRO, Carlos Frederico B. Educação ambiental e movimentos sociais na construção da cidadania ecológica e planetária. In: LOUREIRO, Carlos Frederico B.; LAYRARGUES, Philippe Pomier; CASTRO, Ronaldo Souza de (Org.). Educaşão Ambiental: repensando o espaço da cidadania. São Paulo: Cortez, 2002. p. 69-98.

. Educação Ambiental e Movimentos Sociais: reflexões e questões levantadas no GDP. Pesquisa em Educação Ambiental, v. 3, n. 1, p. 187-201, jan./jun. 2008.

MORIN, Edgar. Ciência com Consciência. Trad. Maria D. Alexandre e Maria Alice Dória. Ed. revista e modificada pelo autor. Rio de Janeiro: Bertrand Brasil, 1996. 336 p.

MOSCOVICI, Serge. Des Représentations Collectives aux Répresentations Sociales: élements pour une histoire. In: JODELET, Denise (Org.). Les representations sociales. Paris: PUF, 1989. p. 62-86.

NORTON, Christine Lynn. Ecopsychology and Social Work: Creating an Interdisciplinary Framework for Redefining Person-in-Environment. Ecopsychology, v. 1, n. 3, p. 138-145, Sept. 2009.

PELICIONI, Maria Cecília Focesi. Fundamentos históricos e filosóficos da Educação Ambiental. Biológico, São Paulo, v. 62, n. 2, p. 303-306, jul./dez. 2000.

PORTUGAL, Francisco Teixeira. A pesquisa-intervenção e o diálogo com os agentes sociais. In: CASTRO, Lucia Rabelo de; BESSET, Vera Lopes (Org.). Pesquisa-intervenção na infância e juventude. Rio de Janeiro: FAPERJ; NAU, 2008. p. 15-20.

REIGOTA, Marcos. O que é educação ambiental. São Paulo: Brasiliense, 1994. 
Cortez, 1999.

- A floresta e a escola: por uma educação ambiental pós-moderna. São Paulo:

. A formação de especialistas em educação ambiental: notas para a discussão. In: SIMPÓSIO COMEMORATIVO AOS 10 ANOS DO CURSO DE EDUCAÇÃO AMBIENTAL E RECURSOS HÍDRICOS, 2005. São Carlos. Anais... São Carlos: USP, 2005. 61-69, 2008.

Cidadania e Educação Ambiental. Psicologia \& Sociedade, Porto Alegre, v. 20, p.

SANTOS, Boaventura de Sousa (Org.) Conbecimento Prudente para uma Vida Decente: Um Discurso sobre as Ciências Revisitado. Porto: Afrontamento, 2003.

Esquerda no Século XXI: As lições do Fórum Social Mundial. Coimbra: Oficina do CES (Centro de Estudos Sociais), 2008.

TOREN, Christina. Making History: the significance of childhood cognition for a comparative anthropology of mind. Man (NS), v. 28, p. 461-478, 1993.

TOURAINE, Alain. A crítica da modernidade. Petrópolis: Vozes, 1994.

VASCONCELLOS, Hedy Silva Ramos; SPAZZIANI, Maria de Lourdes; GUERRA, Antonio Fernando Silveira; FIGUEIREDO, João Batista de Albuquerque. Espaços educativos impulsionadores da Educação Ambiental. Cad. CEDES, Campinas, v. 29, n. 77, p. 29-47, jan./abr. 2009.

Artigo: recebido em 20/11/2009 - aprovado em 21/12/2009 